\title{
Reflections on five decades of the Fontan Kreutzer procedure
}

\author{
Christián Kreutzer $^{1}{ }^{*}$, Jacqueline Kreutzer ${ }^{2}$ and Guillermo O. Kreutzer ${ }^{3}$ \\ ${ }^{1}$ Congenital Heart Surgery, Posadas National Hospital and Austral University Hospital, Buenos Aires, Argentina \\ ${ }^{2}$ Cardiac Catheterization Laboratories, Pittsburgh Children's Hospital, Pittsburgh, PA, USA \\ ${ }^{3}$ Pediatric Cardiac Surgery, Bazterrica Clinic, Buenos Aires, Argentina
}

\section{Edited by:}

Antonio Francesco Corno, University

Sains Malaysia, Malaysia

Reviewed by:

Yves Durandy, CCML, France

K. M. Das, King Fahad Medical City, Saudi Arabia

Vladimiro Vida, University of Padua, Italy

\section{*Correspondence:}

Christián Kreutzer, Congenital Heart Surgery, Posadas National Hospital and Austral University Hospital, Illia y Marconi, El Palomar, Buenos Aires, Argentina

e-mail: maxplus92@yahoo.com
The first successful total right heart bypass via atriopulmonary anastomosis (APA) were reported in 1971 for patients with tricuspid atresia. At the Children's Hospital of Buenos Aires, the cohort of such procedures started in July, when the first fenestrated right heart by pass was performed, with the interposition of a homograft between the right atrial appendage and the main pulmonary artery. In the second patient, instead of placing a homograft, the APA was achieved with the patient's own pulmonary root harvested from the outflow tract of the right ventricle. These techniques were soon replaced in 1978 with the development of the direct valveless posterior APA. Since the very beginning the principle was that the right atrium only functions as a pathway rather than a pump (reason why no inferior vena cava valves were ever used), and the diastolic properties of the systemic ventricle regulate the only real "pump" of this system. The late hemodynamic problems inherent of the APA diminished with modern surgical techniques like the lateral tunnel (LT) or the extracardiac conduit (EC). In spite of the improvement in prognosis and quality of life that the modern techniques have brought for univentricular hearts $(U H)$, with the passing of time, deterioration of this system is frequently seen, due to chronic low cardiac output, elevated central venous pressure making heart transplantation the final stage of treatment. Progressive increase in pulmonary vascular resistances and ventricular dysfunction result in a decline in quality of life and survival. However, the timing of this occurrence is variable, and many survivors enjoy today a satisfactory clinical status. The challenge is to develop a better solution for $\mathrm{UH}$, but in the mean time the Fontan Kreutzer palliation represents the best and only surgical option. It is undoubtedly one of the triumphs of cardiac surgery in congenital heart disease.

Keywords: Fontan Kreutzer, univentricular hearts, heart disease, cardiac surgery, atriopulmonary anastomosis, APA

\section{HISTORY OF THE FIRST ATRIOPULMONARY CONNECTION}

Innovation often results from an unsolved need, as the application of new solutions to meet new requirements. In the early 70 s, our field achieved excellent survival for the most complex forms of biventricular hearts by many centers in the world. However, patients with univentricular hearts (UH) were typically palliated with systemic to pulmonary shunts, pulmonary artery bandings, and partial right heart by pass such as the classic Glenn shunts and other variants (1-3). Therefore a hemodynamic "solution" for UH that was already suggested (4) was required.

The first atriopulmonary anastomosis (APA) was performed without awareness of the pioneer work done by Professor Fontan, published in January 1971 (5). History shows multiple examples of independent discoveries of the same scientific idea or invention (6). Considerable work on multiple simultaneous discoveries has been achieved by William Ogburn and Dorothy Thomas. They established a list of 148 independently duplicated scientific and technological discoveries. They suggested these discoveries became virtually inevitable as knowledge accumulated within any given society and the needs of that society caused attention to be directed toward problems associated with meeting those needs. Similarly, the need to find a solution for single ventricle physiology was clearly there in the early 70s. In July of that same year (1971), a moribund, severely cyanosed 3-year-old boy with tricuspid atresia Ib, was admitted to the cardiology ward at the Ricardo Gutierrez Children's Hospital. He had severe systemic desaturation due to a thrombosed right pulmonary artery due to a previous Waterston shunt (Figure 1A). Contrary to Professor Fontan's first patient for whom two traditional surgical alternatives would have been available (a Blalock-Taussig Shunt or a Glenn procedure), the only theoretical options for this patient were both innovative surgical procedures: the APA (6) or enlargement of the ventricular septal defect (7). It was decided to perform an APA, placing a homograft between the right atrial appendage and the main pulmonary artery without doing a Glenn procedure, without valve implantation in the inferior vena cava. A $6 \mathrm{~mm}$ fenestration at the atrial septum was deliberately left open. This first patient was presented as a case report in August 1971 at a meeting of the Argentinean Society of Cardiology (6) (Figure 1B). Certainly, this was the first fenestrated total right heart by-pass ever performed in the world (8), as stated in the original article: "The total or partial closure of the foramen ovale is a subject of discussion. Although its partial 

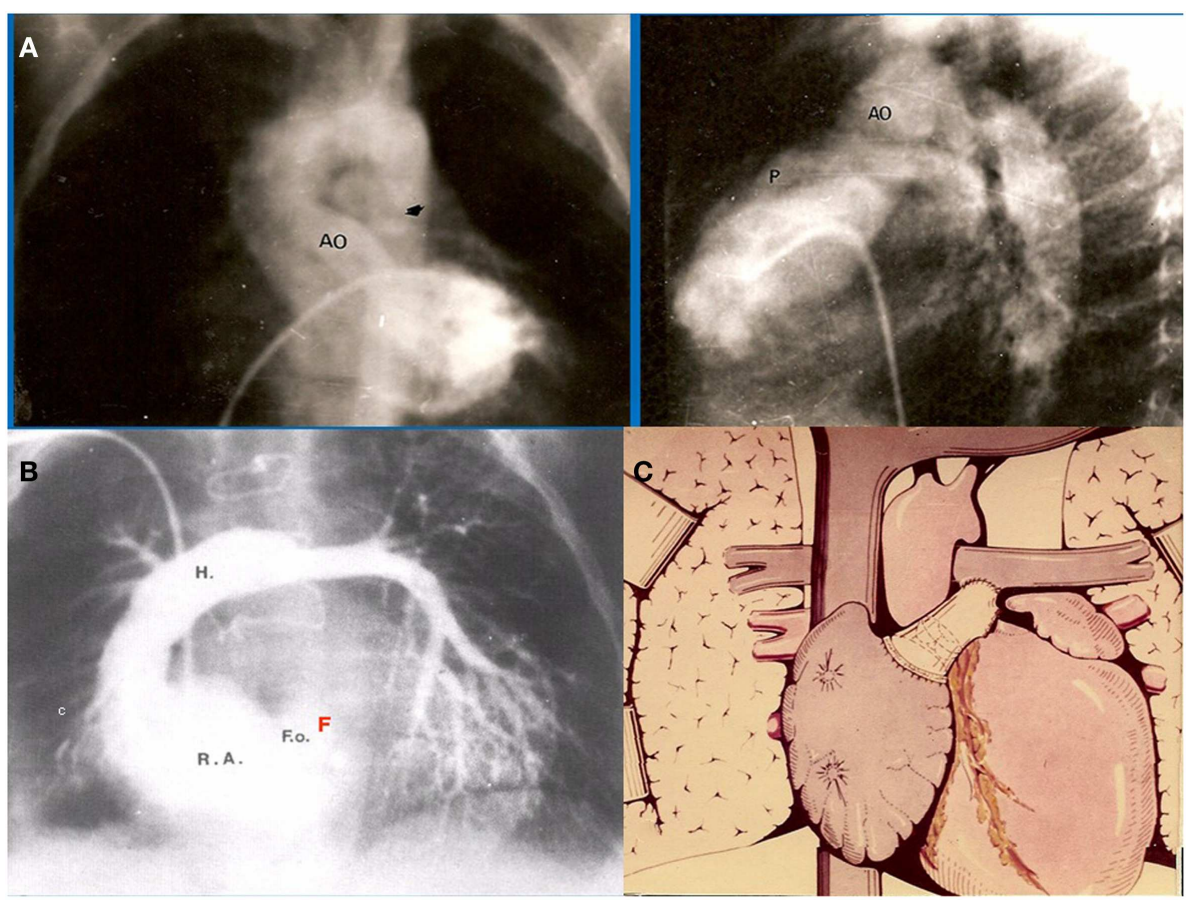

FIGURE 1 | (A) Preoperative angiogram of our first patient showing occluded right pulmonary artery. Only small flow is seen into the left pulmonary artery (B) Postoperative angiogram demonstrates widely patent APA with interposition of a homograft. Note there is a small atrial communication left open, acting as a fenestration (F). (C) Schematic representation of the original APA performed in this patient, communicated in J. Thorac. Cardiovasc. Surg. closure provides a safety valve for the right atrium it also may cause a certain degree of systemic desaturation" (Figure 1C).

Dr. Luis Becú (Figure 2A) who was a superb cardiac morphologist, noticed that in tricuspid atresia Ib the pulmonary valve is most commonly anatomically normal. Therefore, in December 1971 in another patient with the same condition, it was decided to perform the APA directly (Figure 2B) with the patient's own pulmonary root and valve (8), speculating on the possibility of growth and prevention of calcification, following Mr. Ross's guidelines (Figure 2C) on how to remove the pulmonary annulus from the outflow tract of the right ventricle.

Discussions with Drs. Luis Becú and Alberto Rodríguez Coronel (Head of the Cardiac Catheterization Laboratory) on those days were about the following dilemma: is the right atrium functioning as a pump as suggested by Professors Francis Fontan and Viking Bjork (9) or is it just a pathway? The conclusion that the right atrium lacked the tissue properties of a ventricular chamber and therefore would never function as a pump was soon achieved. Furthermore, Dr Rodriguez Coronel emphasized the important role of the end diastolic properties of the main ventricle, acting as a suction pump and therefore being the only pump of the total right heart by pass system. Thus, the right atrium would only function as a pathway and would never do so as a ventricular pump.

Sir Magdi Yacoub, in London expanded the application of the procedure to double outlet left ventricle, reporting in 1975 with a homograft with valves in the superior vena cava and inferior vena cava. Of interest, he performed in one of the patients of his series presenting with subaortic stenosis what we wrongfully call nowadays a Damus-Kaye-Stansel (a pulmonary to ascending aorta anastomosis) procedure for single ventricle and aortic obstruction $(10,11)$. This concept was later re appraised by Dr. William Norwood (12).

The initial experience with the APA was presented at the centennial celebration of the Toronto Sick Children's Hospital in 1975 (13). It was emphasized the importance of "sinus rhythm to reduce left atrial pressure to obtain a reasonable gradient (about $6 \mathrm{mmHg}$ ) between the right and left atrium," and "the left heart being normal." Regarding the need for valves at the inferior vena cava and "outlet" of right atrium it was stated that: "because of the continuous venous flow we doubt that those valves would work adequately and they could increase peripheral venous pressure and the subsequent edema." In this regard, Dr. Rodriguez Coronel acknowledged that the pulmonary valve would be open in the whole cardiac cycle, and only would close in the event of Valsalva o coughing.

Finally, in 1978 it was clear that the interposition of a pulmonary valve was deleterious in this system, even more if associated to obstruction (frequently seen in homografts placed in the right side of the heart). Therefore, the surgical approach was completely changed: the concept of the largest posterior APA without a valve was introduced, moving the pulmonary trunk to the right, posteriorly and behind the aorta (Figure 3), avoiding the possibility of sternal compression. This new approach was presented in 1980 in London (14) at World Congress of Pediatric Cardiology, and published (Figure 4) in several journals $(12,15,16)$. 


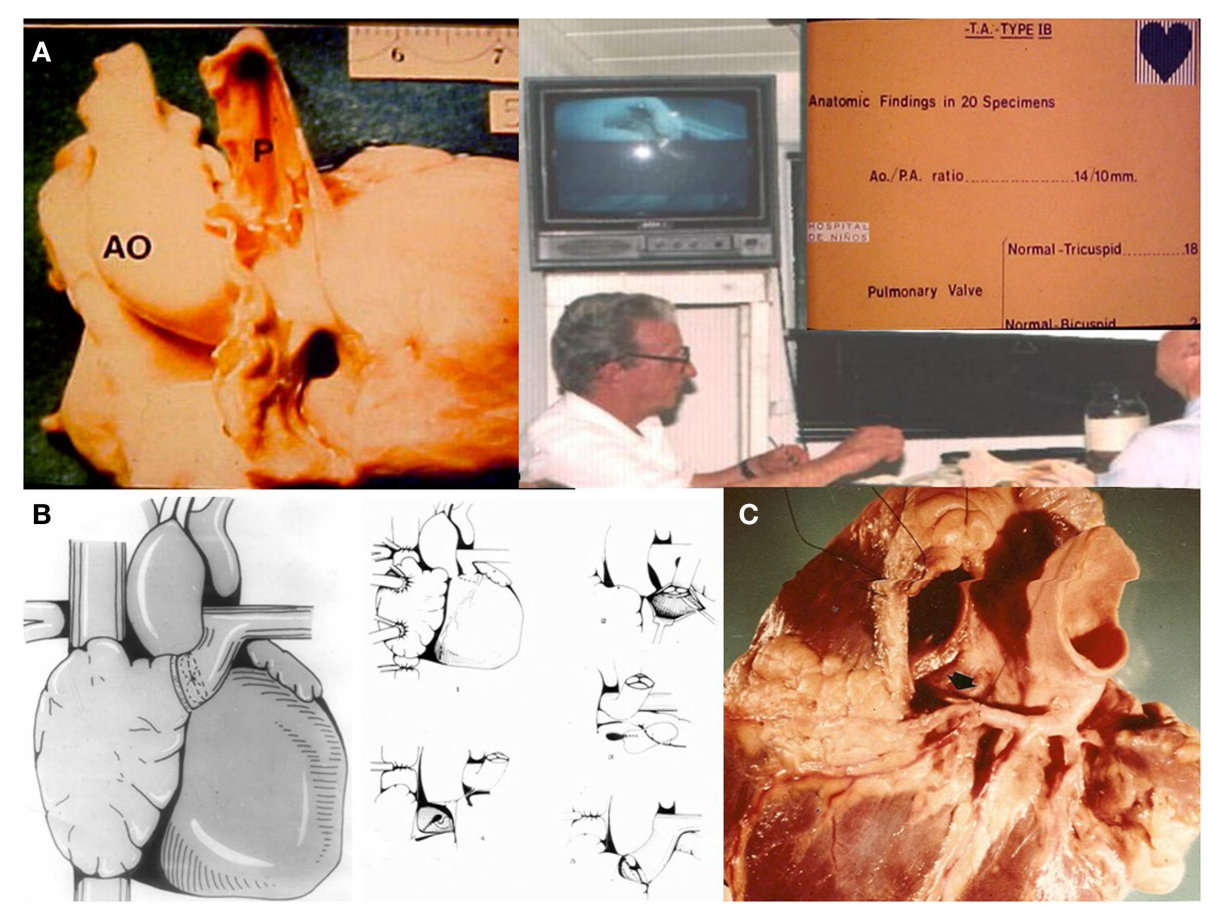

FIGURE 2 | (A) Morphologist Dr. Luis Becú showing that the pulmonary artery is usually normal in TA lb. (B) APA with the patient own pulmonary valve removed from the outflow tract of the right ventricle. (C) Mr. Donald Ross's technique for the removal of the pulmonary annulus.

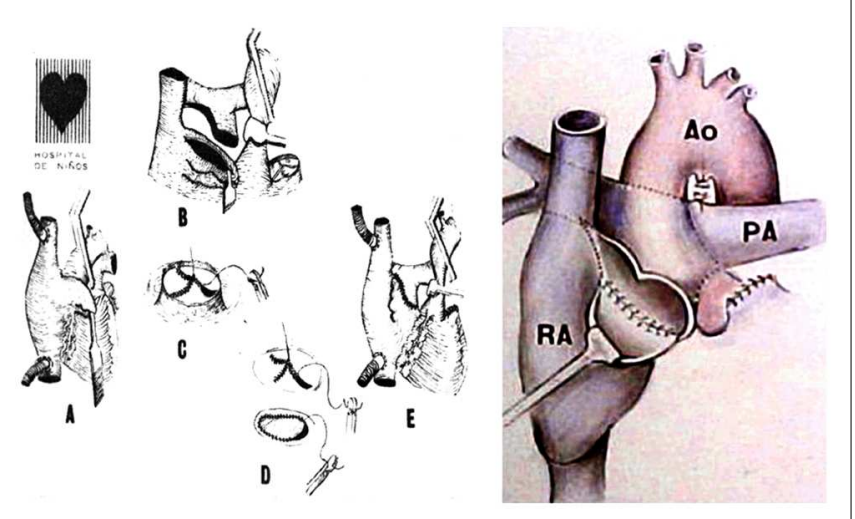

FIGURE 3 | Illustrations demonstrate the steps of the technique used for the posterior APA developed in 1978 presented in London, 1980.

\section{NORWOOD'S REVOLUTION AND DEVELOPMENT OF IMPROVED SURGICAL TECHNIQUES}

In the early 80s Dr. William Norwood at Children's Hospital of Boston and Philadelphia was confronting the biggest challenge in congenital heart surgery: an operation for hypoplastic left heart syndrome (17), a condition that was uniformly lethal at the time. Not only Dr Norwood envisioned the procedure that allowed survival for such complex lesion, he also devised a staged pathway of treatment for all forms of UH. Depending on the initial clinical presentation a neonatal palliation, with a Modified BlalockTaussig Shunt (MBTS), a Norwood procedure or pulmonary artery banding, as a first stage, a bidirectional Glenn or hemiFontan as a second stage in infancy, and the total right heart by pass at $2 / 5$ years of age as a third stage.

The increasing survival of patients with single ventricle and mitral atresia or stenosis, made the atriopulmonary connections inadequate for such patients, since the need for complex atrial septations is mandatory in such scenario. Therefore, when years later, in 1988, Marc de Leval at Great Ormond Street Hospital in London, introduced the accurate concept of energy loss in a passive flow system within a large right atrium $(18,19)$ and described the total cavopulmonary connection (Figure 4A) his technique was widely adopted. Aldo Castañeda with Dr. Lock and Dr. Bridges re introduced the concept of a fenestration as part of the procedure (20) (Figure 4B). Prior to this, in order to avoid complex atrial septation a similar technique had been performed by Dr. Francisco Puga (21) and afterward, Drs Puga (22) and Marcelletti (23) developed the extracardiac conduit technique (EC) (Figures 4C,D), which is since 1997 most surgeons technique of choice for all patients. It can be considered controversial to determine whether the lateral tunnel (LT) or the EC is the best approach. Both techniques have excellent outcomes (20). The approach is often dependent on the preference of the cardiothoracic surgeon and team. It can also be a source of discussion whether a bidirectional Glenn or a hemiFontan is the best option.

Some differences should be pointed out between the staged LT after a bidirectional Glenn versus a hemi-Fontan. When the LT procedure is performed following a bidirectional Glenn preservation of the sinus node and its artery is jeopardized (24). LT is more frequently used in smallest patients commonly at the final 


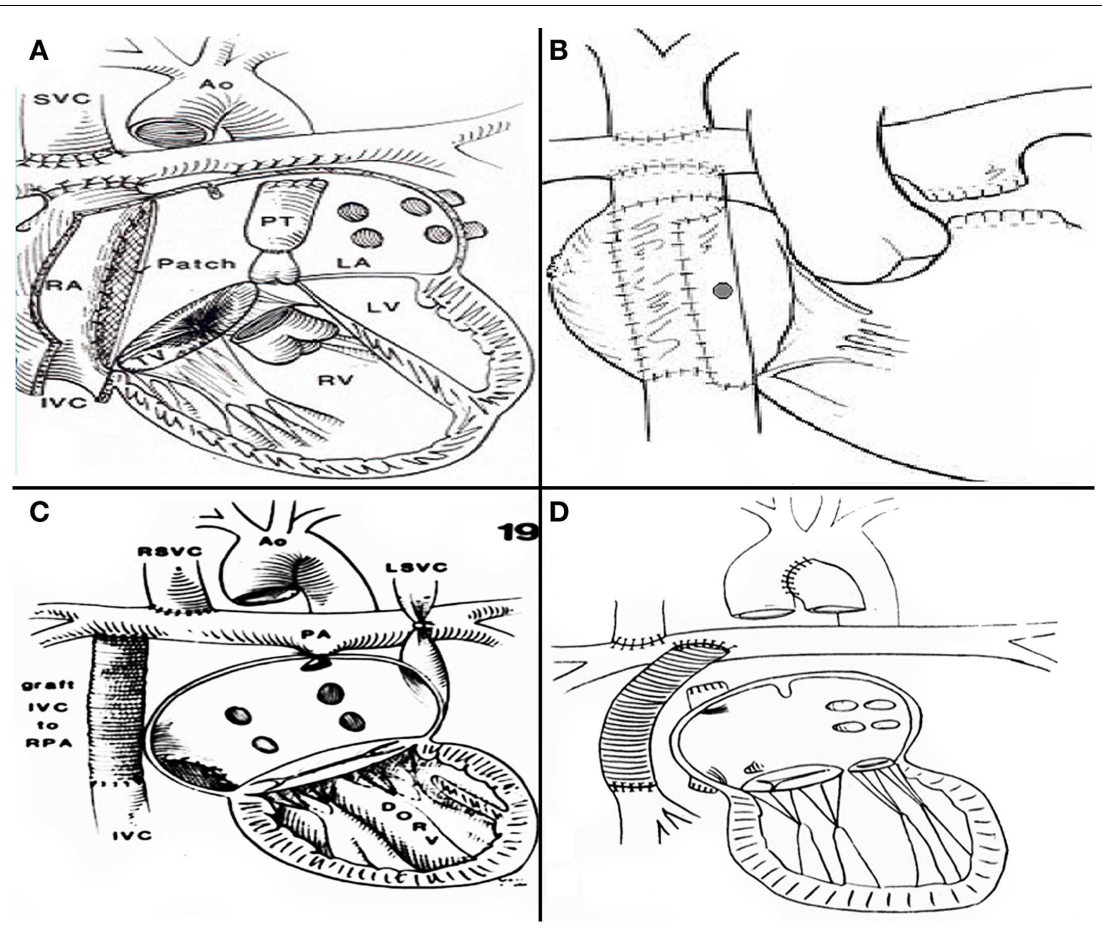

FIGURE 4 | (A) De Leval's total cavopulmonary connection (B) fenestrated lateral tunnel technique. (C) Puga's extracardiac conduit technique (D) Marcelleti's extracardiac conduit technique.

stage of HLHS palliation $(22,23)$. However a weight less than $15 \mathrm{~kg}$ do not preclude the performance of an EC. With the aid of deep hypothermic circulatory arrest for the inferior anastomosis a large conduit of 16-18 $\mathrm{mm}$ can be easily placed in a 1-year-old infant.

The EC has a favorable balance in "bigger" patients considering the following advantages: (1) no intraatrial sutures (2) possibility of performing EC without aortic cross clamp (3) the sinus node and the crista terminalis area remains at low pressure and without suture lines in the area, avoiding injury and subsequent arrhythmias (23) (4) possibility of closing the fenestration without using a device (25). (5) The EC is a cylinder $(18-20 \mathrm{~mm})$ with similar inlet and outlet diameter, different than the LT that it is a truncated cone which its base (the inferior vena cava is larger than the outlet (the superior vena cava). For this reason, fenestration is more necessary with its consequent device closure (26). The presence of bilateral superior vena cava makes the mismatch more evident. In this situation, the EC should be mandatory.

When a hemi-Fontan (27) or a staged LT are performed as the superior vena cava is augmented with a pericardial patch, there is higher risk of injury to the sinus node artery, given its peculiar anatomy (28). It can course in the anterior aspect of the superior vena cava, or on the posterior one or all around it, encircling it. On the other hand, the prosthetic tube of the EC does not increase its diameter (problem for "small" patients), and finally it requires extensive dissection and may induce phrenic nerve palsy (29). The latter may be avoided by using total circulatory arrest, without cannulation of caval veins. The risk of early thromboembolism could be diminished avoiding central venous lines (29). The use of a fenestrated EC with the skirt's technique for fenestration

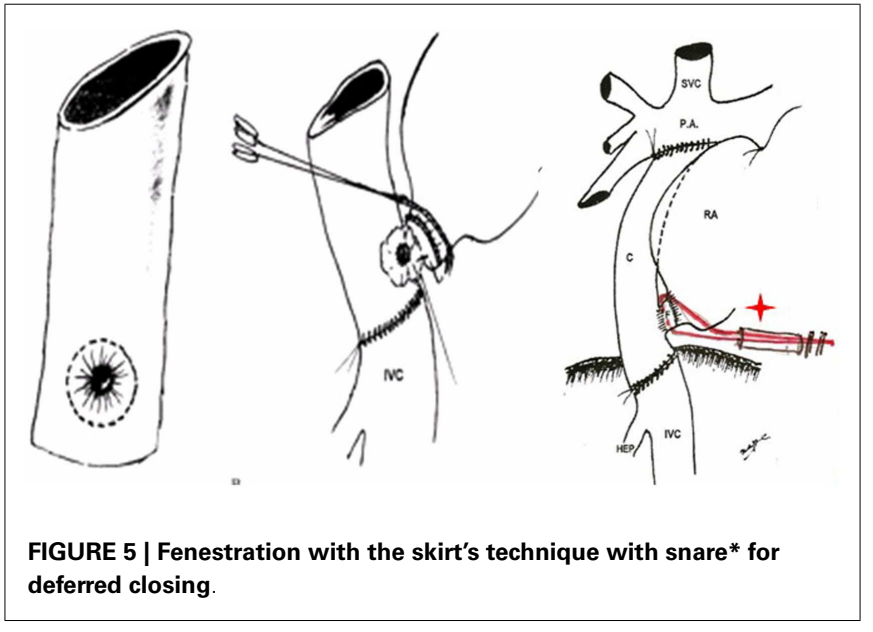

(Figure 5) (25) allows its closure before hospital discharge according to the patient hemodynamics, by adjusting the snare under local anesthesia, without needing a device.

\section{EVOLUTION OF THE SUBOPTIMAL FONTAN KREUTZER HEMODYNAMIC SYSTEM}

The natural history of the univentricular heart without surgery and with palliative procedures as shunts or bandings is disastrous. In spite of chronically limited cardiac output (30), the Fontan Kreutzer procedure has improved significantly $(31,32)$ the prognosis and quality of life. However, to live with only one ventricle has some limitations as a consequence of high venous 
pressure in the limit of the peripheral edema and limited cardiac output. The FK palliation represents without any doubt, the best surgical approach that we could offer today for these lesions. With the modern techniques, the late quality of life is remarkable, with almost $75 \%$ of survivors in NYHA class 1 , in addition to an exercise tolerance of more than $60 \%$ of predicted value $(31,32)$.

In this matter it is quite remarkable that the Fontan Kreutzer procedure is the only palliation that provides the univentricular heart male patient the possibility of having a sexual life, since as a general rule, only a male adult who completes the first two stages of the Bruce protocol has a functional capacity $>7$ METs, which is considered sufficient for sexual intercourse (33). The Fontan Kreutzer procedure provides the vast majority of young adults with $\mathrm{UH}$ a functional capacity of more than seven METs with a mean and median close to 10 (30). On the contrary, a bidirectional Glenn with accessory pulmonary blood flow suggested as a definitive palliation by Professors Vohué and Sidi fails to provide a an exercise capacity of more than six METs in most patients (34).

Pregnancy for patients with a Fontan circulation is more likely to face obstetrical, rather than cardiovascular complications (although a decline in the cardiovascular status is frequently seen in the third trimester), including preterm labor, intrauterine growth restriction, an increased risk of cesarean section, and the potential need for anticoagulation (35).

Of note, we should be very cautious to refer to the classic articles (36) on late follow up after Fontan Kreutzer procedures performed prior 1990, and use these to predict late outcome of our current patients. These represent the results of surgical strategies and procedures that are no longer in use (i.e., long standing pulmonary artery bandings, classic right or left Blalock-Taussig shunts, late intervention, late diagnosis of significant hemodynamic problems, and inadequate surgical techniques such us the classic Fontan and Kreutzer original operations) (Table $\mathbf{1}$ ).

But secondary to a multifactorial phenomenon (Table 1) it is evident that a progressive decline in functional status appears in many the FK survivors, who develop heart failure (30), arrhythmias (37), thromboembolism (38), protein losing enteropathy (39), plastic bronchitis (40), unexplained sudden deaths (41), and hepatic failure $(42,43)$. The reality is that these problems occur as patients do live to late follow up. Under the best circumstances using the modern surgical techniques, at least $80 \%$ of patients with single ventricle are alive after 20 years, following at least three cardiac procedures (32).

For the late survivor with "old fashioned" Fontan Kreutzer connections a conversion to LT or EC with concomitant arrhythmia surgery is indicated only for symptomatic patients with several episodes of arrhythmia in spite of amiodarone treatment or thrombus in the right atrium following Mavroudis's guidelines (44). In failing APA the central tunnel technique may be considered as well (45). However, when ventricular dysfunction is the main determinant of the failure patients should be referred for heart transplant evaluation. Although the results of transplantation in failing single ventricle patients are not optimal, it represents the last viable option for these patients and the final stage of treatment for these patients $(46,47)$ and specially for HLHS. Many concerning associated problems such as renal and hepatic dysfunction can play a significant role in the outcomes. A progressive increase of

\section{Table 1 | Factors that jeopardize the late outcome after a Fontan} Kreutzer procedure.

\author{
Suboptimal surgical approach \\ Classic Fontan \\ Kreutzer APA anastomosis and its variants \\ Bjork atrioventricular connections \\ History of prior long standing PA banding or shunts
}

Increases in pulmonary vascular resistances secondary to

Systemic atrioventricular valve disease (specially history of mitral atresia or stenosis with restrictive-interatrial-communication)

Down's syndrome

Long duration of prior systemic PA shunts or PA distortion

Living at high altitude $(54,55)$

Detrimental effects of chronic use of amiodarone

Subclinical chronic micropulmonary embolism (36)

Pulmonary lymphatic edema (due to increased central venous

pressure) (56)

Chronic lack of pulsatile pulmonary flow (57).

Ventricular dysfunction

Prior long standing volume overload

Inadequate systemic ventricle (right or undetermined ventricle,

cardiomyopathy, or myocardial fibrosis according to the length of time

with chronic hypoxia)

Arrhythmia

AVV incompetence (more frequent in heterotaxy syndrome or HLHS)

Inadequate myocardial protection during prior operations

History of prior systemic out flow tract or arch obstructions treated with PA banding

pulmonary vascular resistances after transplantation for the failing Fontan palliation has also been reported (48).

Of note, there are not many patients who have reached over 50 years of age with a univentricular heart following Fontan Kreutzer palliation. To have reached 50 years of age in 2013 means that the patient was born before 1963, survived the initial palliative procedures and the original Fontan Kreutzer palliation. Of the initial cohort of Buenos Aires among the 14 patients operated upon by the early 70s, 5 are currently alive. All five with a dominant left ventricle: four of these patients had tricuspid atresia and one double inlet left ventricle. Both patients remain in good clinical condition without conversion.

One of the survivors, who was the fifth case of the series presented at Toronto in 1975 (13), is a lady 56 years old (Figure 6A) with TA Ib, who underwent an APA in 1975 at 17 years of age. She is currently, to our knowledge the longest survivor in the world after 39 years of FK palliation. In November 2007, her case was published as a brief communication (49).

For 20 years after surgery this patient led a normal life. She got married, had no pregnancies, and divorced. In the late follow-up she developed intermittent atrial fibrillation and the homograft became stenotic and calcified. She was treated with amiodarone and anticoagulation, as she originally refused surgical conversion. At age 49, she was overtly symptomatic, with hydrothorax (Figure 6B), atrial fibrillation (Figure 7A), and a large intra atrial 


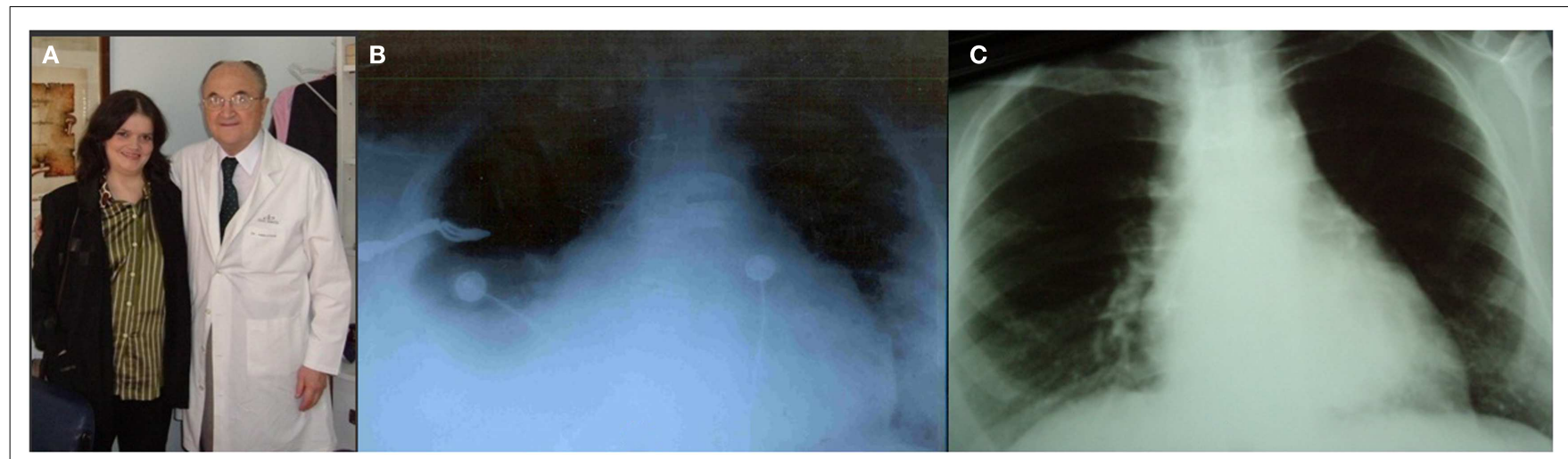

FIGURE 6 | (A) Patient aged 53 years with TA Ib. After 34 years of Fontan Kreutzer palliation. (B) Pre-reconversion chest Roentgenogram. (C) Chest Roentgenogram 1 year after conversion.

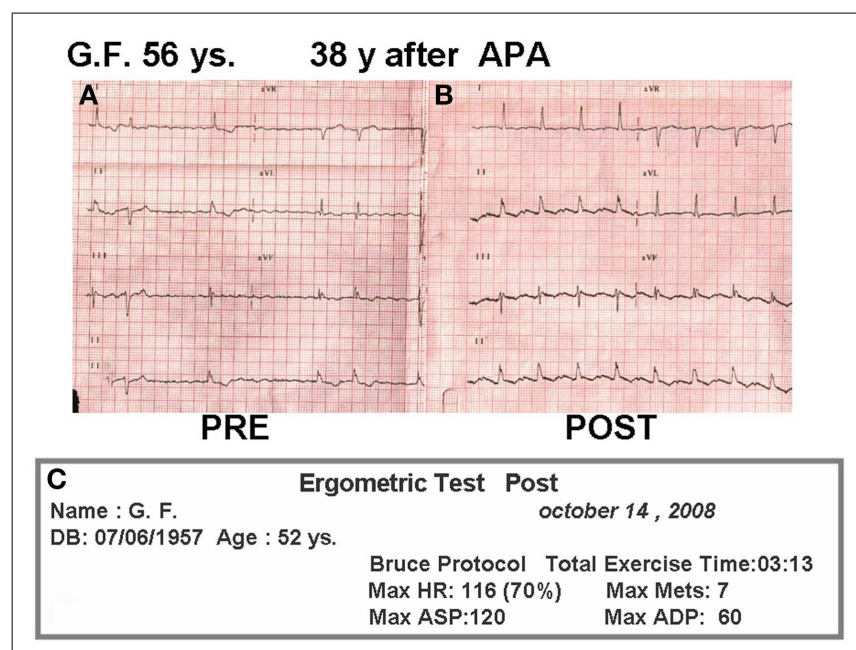

FIGURE 7 | (A) Pre-reconversion ECG. (B) ECG 2 years after conversion. (C) Treadmill test 2 years after conversion.

thrombus. Fortunately her left ventricular function was preserved. Conversion to a fenestrated EC with extraction of homograft and thrombus was performed on May 2006. Now, after 7 years following conversion, she is in good clinical condition (Figure 6C) in sinus rhythm (Figure 7B) and with an exercise test achieving seven METs (Figure 7C).

\section{CONCLUSION}

The durability of the suboptimal Fontan Kreutzer hemodynamic system is affected by many variables, patient, procedural, and management related. Several hypotheses could explain the deterioration of this system with the passing of time, particularly in patients with forms other than the "perfect" tricuspid atresia. Several adverse factors may lead to chronic gradual increase in the right side venous pressure: Table 1.

With the development of better surgical management, the outcome of the FK procedure seems to have improved over the years. The current long-term results using the modern surgical alternatives are excellent $(31,32,50-52)$. The challenge is to reproduce this outcome for the vast majority of patients, and to develop viable alternatives to deal with late failure.

As physicians involved in the care of the most complex form of congenital heart disease, our future goal would be to seek a better surgical procedure to improve the long-term outcome of patients with UH. May it be a complete or partial mechanical device (53) or improved heart transplantation availability and outcomes. In the meantime, the Fontan Kreutzer palliation, which seemed to be a radical approach in the 70 s, has become a routine procedure world wide, and continues to represent the best surgical option we can offer to these patients. It is clearly, one of the triumphs of cardiac surgery in congenital heart disease.

\section{REFERENCES}

1. Glenn WL. Circulatory bypass of the right heart. Yale J Biol Med (1954) 27(3):147-51.

2. Carlon CA, Mondini PG, de Marchi R. Surgical treatment of some cardiovascular disease (a new vascular anastomosis). J Int Coll Surg (1951) 16:1-11.

3. Azzolina G, Eufrate S, Pensa P. Tricuspid atresia: experience in surgical management with modified cavo-pulmonary anastomoses. Thorax (1972) 27:111-5. doi:10.1136/thx.27.1.111

4. Robicsek F, Sanger PW, Gallucci V. Long term complete circulatory exclusion of the right side of the heart. Hemodynamics observations. Am J Cardiol (1966) 18(6):867-75. doi:10.1016/0002-9149(66)90432-2

5. Fontan F, Baudet P. Surgical repair of tricuspid atresia. Thorax (1971) 26:240-8. doi:10.1136/thx.26.3.240

6. Kreutzer G, Galíndez E, Bono H. Una operación para la corrección de la atresia tricuspídea. Fifth Scientific Meeting of the Argentinian Society of Cardiology, Buenos Aires. (1971).

7. Brock P. Tricuspid atresia. A step toward corrective treatment. J Thorac Cardiovasc Surg (1964) 47:17-25.

8. Kreutzer G, Galíndez E, Bono H, De Palma C, Laura JP. An operation for the correction of tricuspid atresia. J Thorac Cardiovasc Surg (1973) 66: 613-21.

9. Bjork VO, Olin CL, Bjarke BB, Thorén CA. Right atrial-right ventricular anastomosis for correction of tricuspid atresia. J Thorac Cardiovasc Surg (1979) 77:452-8.

10. Yacoub M, Ahmed M, Radley-Smith R. Proceedings: use of right atrium to pulmonary artery valved conduit for 'correction' of single ventricle of hypoplastic right heart syndrome. Br Heart J (1975) 37(7):78.

11. Yacoub MH, Radley-Smith R. Use of a valved conduit from right atrium to pulmonary artery for "correction" of single ventricle. Circulation (1976) $\mathbf{5 4}(6$ Suppl):III63-70.

12. Kreutzer GO, Allaria AE, Schlichter AJ, Roman MI, Capelli H, Berri GG, et al. A comparative long term follow up of the results of anterior and posterior 
approaches in bypassing the rudimentary right ventricle in patients with Tricuspid Atresia. Int J Cardiol (1988) 19(2):167-79. doi:10.1016/0167-5273(88) 90077-0

13. Kreutzer G. Recent surgical approach to tricuspid atresia. In: Kidd BS, Rowe RD editors. The Child with Congenital Heart Disease After Surgery. New York: Futura Publishing Company (1975). p. 85-97.

14. Kreutzer G, Schlichter A, Laura JP, et al. Univentricular heart with low pulmonary vascular resistances: septation vs. atriopulmonary anastomosis. Read in the World Congress of Pediatric Cardiology. London: Congress Book (1980).

15. Kreutzer G, Schlichter A, Laura JP, Suárez JC, Vargas JF. Univentricular heart with low pulmonary vascular resistances: septation vs. atriopulmonary anastomosis. Arq Bras Cardiol (1981) 37:301-7.

16. Kreutzer GO, Vargas FJ, Schlichter AJ, Laura JP, Suarez JC, Coronel AR, et al. Atriopulmonary anastomosis. J Thorac Cardiovasc Surg (1982) 83: 427-36.

17. Norwood WI, Kirklin JK, Sanders SP. Hypoplastic left heart syndrome: experience with palliative surgery. Am J Cardiol (1980) 45(1):87-91. doi:10.1016/ 0002-9149(80)90224-6

18. de Leval MR, Kilner P, de Leval MR, Kilner P, Gewillig M, Bull C. Total cavopulmonary connection: a logical alternative to atriopulmonary connections for complex Fontan Operations. Experimental studies and early clinical experience. J Thorac Cardiovasc Surg (1988) 96:687.

19. de Leval MR, Dubini G, Migliavacca F, Jalali H, Camporini G, Redington A, et al. Use of computational fluid dynamics in the design of surgical procedures: application to the study of competitive flows in cavopulmonary connections. J Thorac Cardiovasc Surg (1996) 111:502-13. doi:10.1016/S0022-5223(96) 70302-1

20. Jonas RA, Castaneda AR. Modified Fontan procedure: atrial baffle and systemic venous to pulmonary artery anastomosis techniques. J Card Surg (1988) 3:91-6. doi:10.1111/j.1540-8191.1988.tb00228.x

21. Puga FJ, Chavareli M, Hagler DJ. Modification of the Fontan operation applicable to the patients with left atriovascular valva. Circulation (1987) 76(3 Pt 2):11153-60.

22. Humes RA, Feldt RH, Porter CJ, Julsrud PR, Puga FJ, Danielson GK. The modified Fontan operation for asplenia and polysplenia syndromes. J Thorac Cardiovasc Surg (1988) 96:212-8.

23. Marceletti C, Corno A, Giannico S, Marino B. Inferior vena cava-pulmonary artery extracardiac conduit: a new form of right heart by pass. J Thorac Cardiovasc Surg (1990) 100:228-32.

24. Manning PB, Mayer JE Jr, Wernovsky G, Fishberger SB, Walsh EP. Staged operation to Fontan increases the incidence of sinoatrial node dysfunction. J Thorac Cardiovasc Surg (1996) 4:833-40. doi:10.1016/S0022-5223(96)70344-6

25. Kreutzer C, Schlichter AJ, Simon JL, Conejeros Parodi WM, Blunda C, Kreutzer GO. A new method for reliable fenestration in extracardiac conduit. Ann Thorac Surg (2003) 75:1657-9. doi:10.1016/S0003-4975(02)04569-1

26. Bridges N, Lock J, Castaneda A. Baffle fenestration with subsequent trasncatheter closure. Modification of the Fontan operation for patients at increased risk. Circulation (1990) 82:1681-9. doi:10.1161/01.CIR.82.5.1681

27. Douville EC, Sade RM, Fyje DA. Hemi-Fontan operation in surgery for single ventricle: a preliminary report. Ann Thorac Surg (1991) 51:893-900. doi:10.1016/0003-4975(91)91000-L

28. Anderson RH, Becker AE. In: Stark J, de Leval M editors. Surgery for Congenital Heart Defects. Chapter 1. Philadelphia: W.B. Saunders Company (1994). 35 p.

29. Jacobs ML, Pelletier GJ, Pourmoghadam KK, Mesia CI, Madan N, Stern $\mathrm{H}$, et al. Protocols associated with no mortality in 100 consecutive Fontan procedures. Eur J Cardiothorac Surg (2008) 33:626-32. doi:10.1016/j.ejcts.2007. 12.032

30. Lawrenson J, Gewillig M. The ventricle in the functionally ventricular heart. The Right Heart in Congenital Heart Disease. London: Greenwich Medical Media (1998). p. 127-36.

31. Giannico S, Hammad F, Amodeo A, Michielon G, Drago F, Turchetta A, et al. Clinical outcome of 193 extracardiac Fontan patients: the first 15 years. J Am Coll Cardiol (2006) 47(10):2065-73. doi:10.1016/j.jacc.2005.12.065

32. Brown JW, Ruzmetov M, Deschner BW, Rodefeld MD, Turrentine MW. Lateral tunnel Fontan in the current era: is it still a good option? Ann Thorac Surg (2010) 89(2):556-62. doi:10.1016/j.athoracsur.2009.10.050

33. Sainz I, Amaya J, Garcia M. Erectile dysfunction in heart disease patients. Int J Impot Res (2004) 16(Suppl 2):S13-7. doi:10.1038/sj.ijir.3901124
34. Gérelli S, Boulitrop C, Van Steenberghe M, Maldonado D, Bojan M, Raisky $\mathrm{O}$, et al. Bidirectional cavopulmonary shunt with additional pulmonary blood flow: a failed or successful strategy? Eur J Cardiothorac Surg (2012) 42(3):513-9. doi:10.1093/ejcts/ezs053

35. Canobbio MM, Mair DD, van der Velde M, Koos BJ. Pregnancy outcomes after the Fontan repair. J Am Coll Cardiol (1996) 28(3):763-7. doi:10.1016/07351097(96)00234-3

36. Bull K. The Fontan procedure: lessons from the past. Heart (1998) 79(3):213-4.

37. Frankin R. The Fontan circulation: risk factors. In: Redington A editor. The Right Heart in Congenital Heart Disease. London: Greenwich Medical Media (1998). p. 137-44.

38. Coon PD, Rychik J, Novello RT, Ro PS, Gaynor JW, Spray TL. Thrombus formation after Fontan operation. Ann Thorac Surg (2001) 71:1990-4. doi:10.1016/S0003-4975(01)02472-9

39. Rychk J. Protein losing enteropathy after Fontan operation. Congenit Heart Dis (2007) 2:288-300. doi:10.1111/j.1747-0803.2007.00116.x

40. Caruthers RL, Kempa M, Loo A, Gulbransen E, Kelly E, Erickson SR, et al. Demographic characteristics and estimated prevalence of Fontan-associated plastic bronchitis. Pediatr Cardiol (2013) 34(2):256-61. doi:10.1007/s00246012-0430-5

41. Khairy P, Fernandes SM, Mayer JEJr, Triedman JK, Walsh EP, Lock JE, et al. Long-term survival modes of death and predictors of mortality in patients with Fontan. Surg Circ (2008) 117:85-92. doi:10.1161/CIRCULATIONAHA. 107.738559

42. Johnson JA, Cetta F, Graham RP, Smyrk TC, Driscoll DJ, Phillips SD, et al. Identifying predictors of hepatic disease in patients after the Fontan operation: a postmortem analysis. J Thorac Cardiovasc Surg (2013) 146(1):140-5. doi:10.1016/j.jtcvs.2012.09.005

43. Kiesewetter CH, Sheron N, Vettukattill JJ, Hacking N, Stedman B, MillwardSadler H, et al. Hepatic changes in the failing Fontan circulation. Heart (2007) 93:579-84. doi:10.1136/hrt.2006.094516

44. Mavroudis C, Deal BJ, Backer CL, Johnsrude CL. The favorable impact of arrhythmia surgery of total cavopulmonary artery Fontan conversion. Semin Thorac Cardiovasc Surg Pediatr Card Surg Annu (1999) 2:143-56.

45. Kreutzer C, Schlichter A, Kreutzer G. Cavo atriopulmonary anastomosis via nonprosthetic central tunnel. J Card Surg (1997) 12:36-40. doi:10.1111/j.15408191.1997.tb00086.x

46. Davies RR, Sorabella RA, Yang J, Mosca RS, Chen JM, Quaegebeur JM. Outcomes after transplantation for "failed" Fontan: a single-institution experience. J Thorac Cardiovasc Surg (2012) 143(5):1183-92. doi:10.1016/j.jtcvs.2011.12.039

47. Mitchell MB, Campbell DN, Ivy D, Boucek MM, Sondheimer HM, Pietra B, et al. Evidence of pulmonary vascular disease after heart transplantation for Fontan circulation failure. J Thorac Cardiovasc Surg (2004) 128:693-702. doi:10.1016/j.jtcvs.2004.07.013

48. Petko M, Myung RJ, Wernovsky G, Cohen MI, Rychik J, Nicolson SC, et al. Surgical reinterventions following the Fontan procedure. Eur J Cardiothorac Surg (2003) 24:255-9. doi:10.1016/S1010-7940(03)00257-4

49. Kreutzer GO. Thirty-two years after total right heart bypass. J Thorac Cardiovasc Surg (2007) 134:1351-2. doi:10.1016/j.jtcvs.2007.02.057

50. Kim SJ, Kim WH, Lim HG, Lee JY. Outcome off 200 patients after an extracardiac Fontan procedure. J Thorac Cardiovasc Surg (2008) 136:108-16. doi:10.1016/j.jtcvs.2007.12.032

51. Ohuchi H, Kagisaki K, Miyazaki A, Kitano M, Yazaki S, Sakaguchi H, et al. Impact of the evolution of the Fontan operation on early and late mortality: a single-center experience of 405 patients over 3 decades. Ann Thorac Surg (2011) 92(4):1457-66. doi:10.1016/j.athoracsur.2011.05.055

52. Fiore AC, Turrentine M, Rodefeld M, Vijay P, Schwartz TL, Virgo KS, et al. Fontan operation: a comparison of lateral tunnel with extracardiac conduit. Ann Thorac Surg (2007) 83:622-30. doi:10.1016/j.athoracsur.2006.09.070

53. Delorme Y, Anupindi K, Kerlo AE, Shetty D, Rodefeld M, Chen J, et al. Large eddy simulation of powered Fontan hemodynamics. J Biomech (2013) 46(2):408-22. doi:10.1016/j.jbiomech.2012.10.045

54. Johnson JT, Lindsay I, Day RW, Van Dorn CS, Hoffman J, Everitt MD, et al. Living at altitude adversely affects survival among patients with a Fontan procedure. I Am Coll Cardiol (2013) 61(12):1283-9. doi:10.1016/j.jacc.2013.01.008

55. Zhou Z, Malhotra SP, Yu X, Rutledge J, Rebeyka IM, Ross DB, et al. Moderate altitude is not associated with adverse postoperative outcomes for patients undergoing bidirectional cavopulmonary anastomosis and Fontan operation: a 
comparative study among Denver, Edmonton, and Toronto. J Thorac Cardiovasc Surg (2013) 146(5):1165-71. doi:10.1016/j.jtcvs.2012.12.073

56. Laine GA, Allen SJ, Katz J, Gabel JC, Drake RE. Effect of systemic venous pressure elevation of lymph flow and lung edema formation. J Appl Physiol (1986) 6:1634-8.

57. de Leval M. Pulmonary hemodynamics and the Fontan circulation. In: Redington RN editor. The Right Heart in Congenital Heart Disease. London: Greenwich Medical Media (1998). p. 113-6.

Conflict of Interest Statement: The authors declare that the research was conducted in the absence of any commercial or financial relationships that could be construed as a potential conflict of interest.
Received: 11 September 2013; accepted: 29 November 2013; published online: 18 December 2013.

Citation: Kreutzer C, Kreutzer J and Kreutzer GO (2013) Reflections on five decades of the Fontan Kreutzer procedure. Front. Pediatr. 1:45. doi: 10.3389/fped.2013.00045

This article was submitted to Pediatric Cardiology, a section of the journal Frontiers in Pediatrics.

Copyright (C) 2013 Kreutzer, Kreutzer and Kreutzer. This is an open-access article distributed under the terms of the Creative Commons Attribution License (CC BY). The use, distribution or reproduction in other forums is permitted, provided the original author(s) or licensor are credited and that the original publication in this journal is cited, in accordance with accepted academic practice. No use, distribution or reproduction is permitted which does not comply with these terms. 